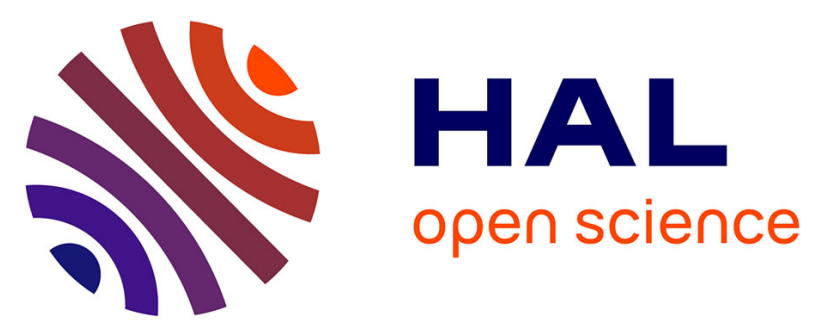

\title{
Auto-ignition control using an additive with adaptable chemical structure. Part II: Development of a PRF kinetic model including 1,3- cyclohexadiene mechanism and simulations of ignition control
}

Alessandro Schönborn, Minh Duy Le, René Fournet, Pierre-Alexandre Glaude, Valérie Warth, Baptiste Sirjean

\section{To cite this version:}

Alessandro Schönborn, Minh Duy Le, René Fournet, Pierre-Alexandre Glaude, Valérie Warth, et al.. Auto-ignition control using an additive with adaptable chemical structure. Part II: Development of a PRF kinetic model including 1,3- cyclohexadiene mechanism and simulations of ignition control. Energy \& Fuels, 2019, 33 (12), pp.12704-12713. 10.1021/acs.energyfuels.9b02020 . hal-02938824

\author{
HAL Id: hal-02938824 \\ https://hal.science/hal-02938824
}

Submitted on 15 Sep 2020

HAL is a multi-disciplinary open access archive for the deposit and dissemination of scientific research documents, whether they are published or not. The documents may come from teaching and research institutions in France or abroad, or from public or private research centers.
L'archive ouverte pluridisciplinaire HAL, est destinée au dépôt et à la diffusion de documents scientifiques de niveau recherche, publiés ou non, émanant des établissements d'enseignement et de recherche français ou étrangers, des laboratoires publics ou privés. 


\title{
Auto-ignition control using an additive with
}

\author{
adaptable chemical structure. Part II: Development
}

of a PRF kinetic model including 1,3-

cyclohexadiene mechanism and simulations of ignition control

Alessandro Schönborn ${ }^{*},+$, Minh Duy Le ${ }^{*}$, René Fournet ${ }^{*}$, Pierre-Alexandre Glaude ${ }^{*}$, Valérie Warth $^{+}$Baptiste Sirjean ${ }^{*,+}$

†World Maritime University, Fiskehamnsgatan 1, 20124 Malmö, Sweden

\#aboratoire Réactions et Génie des Procédés, Université de Lorraine, CNRS, LRGP, F-54000 Nancy, France 
ABSTRACT: Autoignition control of fuel and air mixtures was simulated using an additive able to change its molecular structure upon light irradiation. This control was assumed to be feasible through the photochemical isomerisation of 1,3-cyclohexadiene (1,3-CHD) to cis-1,3,5hexatriene (1,3,5-HT). 1,3-CHD was present in a molar concentration of $1 \%$ in a PRF fuel, and was transformed into 1,3,5-HT in varying amounts prior to ignition, in an attempt to control autoignition timing. The autoignition delays were calculated using a newly developed chemical kinetic mechanism for the low temperature combustion of PRF / 1,3-CHD / 1,3,5-HT mixtures in air. Validations for PRF / air mixture were performed by simulations based on the new mechanism developed in the current work against ignition delay times (IDT) of the literature measured in rapid compression machines. The agreement between simulations and experiments for the pure compounds reinforced the accuracy of the mechanism, which led to an investigation of its impact on the IDTs for the addition of 1,3-CHD to PRF90. The computations showed that 1,3-CHD was an ignition enhancer, with a similar boosting effect as 2-ethylhexyl nitrate. Simulations predicted that the extent of ignition enhancing of 1,3-CHD can be controlled by the pressure because of the specific combustion chemistry that rules the ignition enhancing capacity of this compound. Additions of 1,3-CHD were found to promote the reactivity of a PRF90 to a greater extent than the addition of 1,3,5-HT. Simple single-zone modelling showed that ignition in a homogeneous charge compression ignition (HCCI) engine may be controlled if the fuel is photochemically isomerised using light-irradiation prior to the combustion process. 


\section{INTRODUCTION}

Several advanced concepts for internal combustion engines or gas turbine applications require a detailed control of the autoignition delays of the fuel. For example, in the Homogeneous Charge Compression Ignition (HCCI) concept, the timing of combustion is controlled by the autoignition of the homogeneous fuel-air mixture. Over the last decades, several approaches have been investigated to efficiently control autoignition in a HCCI engine. ${ }^{1}$ Ignition should be controlled to an optimal point around TDC, which offers the highest thermal efficiency of the cycle, since too early or too late ignition will result in poor thermal efficiency. One of the latest strategies proposed in the literature to control HCCI combustion timing relies on the utilization of two different fuels. This is the concept of Reactivity Controlled Compression Ignition (RCCI) where the control of the combustion timing is achieved by using a variable mixture of a low-reactivity fuel (e.g., gasoline) and a high-reactivity fuel (e.g., Diesel) stratified throughout the combustion chamber. ${ }^{2}$ Experiments in laboratory engines have shown that RCCI allows up to a $20 \%$ increase of fuel efficiency over standard Diesel and 40-50\% over SI gasoline engines, with ultra-low NOx and PM emissions. ${ }^{3}$ The fundamental need of using two fuels in RCCI is also a disadvantage since two separate fuel tanks need to be replenished when refueling the vehicle. To eliminate the need for filling two main fuel tanks with different fuels, several strategies rely on the chemical transformation of a single-fuel to produce two fuels of different reactivity, such as fuel reforming ${ }^{4}$ and peroxide formation within the fuel through ozone addition ${ }^{5}$ or photochemistry ${ }^{6}$ can be considered. 
In this work, ignition quality is controlled via a reversible photochemical reaction applied prior to ignition, for the first time the combustion process is modelled using a new detailed and validated chemical kinetic mechanism. The mechanism was purposely developed for a primary reference fuel (PRF) containing 1,3-cyclohexadiene (1,3-CHD) and cis-1,3,5-hexatriene (1,3,5HT).

Using simulations, the photochemical isomerisation of 1,3-CHD to 1,3,5-HT was used to adapt the molecular structure of the fuel, and thereby influence its ignition reactions with air. The fuel tested consisted of a volume fraction of $99 \%$ PRF90 and $1 \%$ 1,3-CHD. The PRF90 consisted of $90 \%$ iso-octane, and $10 \% n$-heptane by volume fractions. The $1,3-\mathrm{CHD}$ acted as the photochemically active additive, and was in some of the simulations partly photochemically isomerised to $1,3,5-\mathrm{HT}$. The photochemical isomerisation was assumed to take place via light irradiation with light at $\lambda=265 \mathrm{~nm}$ wavelength. In the experiments of Minnaard and Havinga ${ }^{7}$, an $80 \%$ conversion of 1,3-CHD to $1,3,5-\mathrm{HT}$ was obtained after less than $220 \mathrm{~min}$, at a quantum yield of 0.4 . The light energy required for the photochemical reaction, thus theoretically represents $0.3 \%$ of the fuel energy. Figure 1 presents a schematic representation of an HCCI engine functioning with a photochemical fuel isomerization. 


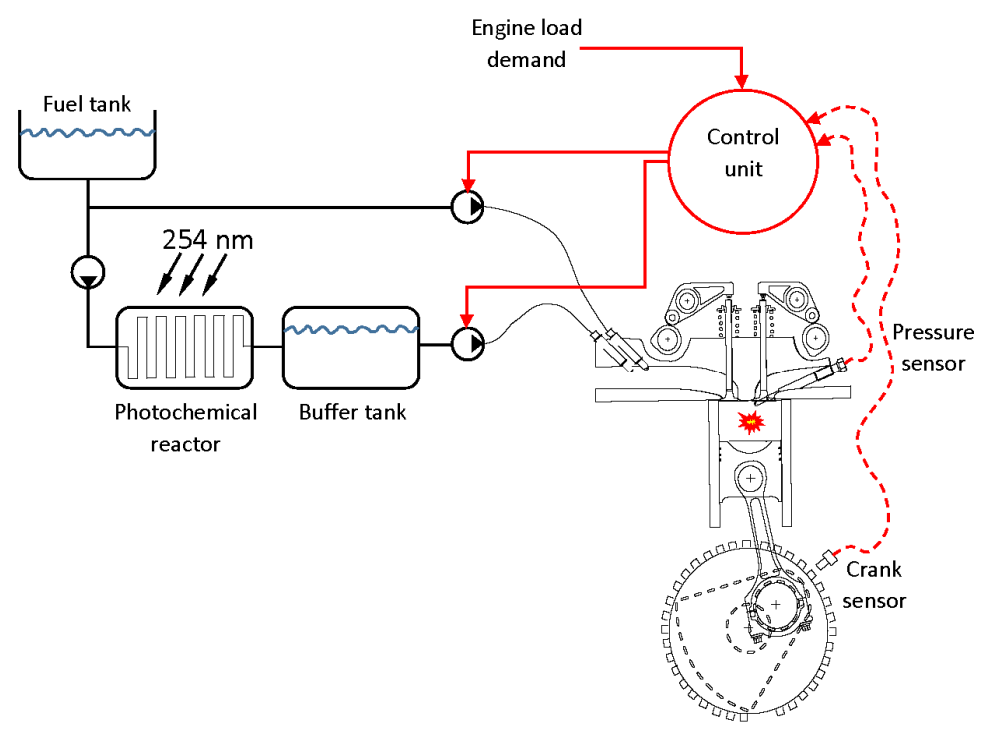

Figure 1. Photoreactive fuel isomerisation and HCCI engine with pressure sensor

A pressure sensor and a crank sensor can be used to measure the time of ignition within the cycle. The time of ignition within the cycle can be compared with the optimal ignition timing, to adjust of the fraction of converted and unconverted fuel in the engine to their ideal proportions using feedback control. The reaction time required to reach a photochemical conversion of $80 \%$ in the original experiments of Minnaard and Havinga ${ }^{7}$ is several orders of magnitude larger than the time-scale at which an engine needs to respond to transient changes in operation. This dilemma can be solved by making photochemically converted fuel available instantaneously from a buffer tank. The photochemically converted fuel in the buffer tank is replenished using a photochemical reactor of high conversion capacity, which reduces fuel conversion time to the necessary scale. As long as the photochemical reactor has sufficient conversion capacity, the needs of the engine in terms of photochemically converted fuel can be covered. The reactor should aim to use a high efficiency light-source, such as light emitting diodes. The buffer tank 
will not have to be refilled by the vehicle operator, but can be replenished using photochemical conversion of a single fuel supplied to the vehicle.

\section{KINETIC MODELLING METHOD}

A detailed chemical kinetic model was developed to simulate the low and intermediate temperature combustion (500 - $1200 \mathrm{~K}$ ) of a PRF, using automatic generation to create a trial mechanism that was improved using iterative simulations / rate parameters adjustments. To simulate the effect of the 1,3-CHD on the PRF, the kinetic model developed for the combustion of 1,3-CHD and 1,3,5-HT in our previous work ${ }^{8}$ was added to the PRF model. The final kinetic model is therefore resulting from the merging of these two mechanisms (PRF $+1,3-\mathrm{CHD})$. The validation of the kinetic model is based on simulations of auto-ignition delays measured in rapid compression machines (RCM). In the literature, such data have been reported by Tanaka et al. ${ }^{9}$ for various PRF compositions and for pure 1,3-CHD, at conditions relevant to HCCI combustion: equivalence ratios ranging from 0.2 to 0.5 at pressures around 42 bar and temperatures between 800 and $900 \mathrm{~K}$.

The detailed chemical kinetic model for 1,3-CHD / 1,3,5-HT / PRF combustion was developed using the following method:

- a trial PRF kinetic model was automatically generated, using the EXGAS software, ${ }^{10,11}$

- the trial mechanism was adjusted to better reproduce experimental data measured in a RCM, 
- the validated PRF and 1,3-CHD kinetic models were merged together, relying on common reaction basis.

In the following paragraphs, the development and validation of the PRF model is presented.

The PRF (n-heptane and iso-octane) kinetic model was generated using the EXGAS software. ${ }^{10,11}$ The system automatically creates a reaction mechanism and the associated thermochemical and kinetic data. The reaction mechanism generator produces three blocks: a reaction base (core mechanism), a primary and a secondary mechanism.

The core mechanism adopted in the PRF kinetic model is the same as the one described in details in the 1,3-CHD kinetic mechanism. ${ }^{8}$ It includes a $\mathrm{C}_{0}-\mathrm{C}_{2}$ reaction basis, extended with $\mathrm{C}_{3}-$ $\mathrm{C}_{4}{ }^{12}$ and updated cyclopentadiene and benzene $\left(\mathrm{C}_{5}-\mathrm{C}_{6}\right)$ reaction basis. ${ }^{13,14}$

The second block of reactions generated by the EXGAS software is a comprehensive primary mechanism. In this mechanism, only the initial reactants and oxygen react following the rules of generation. For the generation of n-heptane and iso-octane combustion kinetic models, the following reactions were included for the primary mechanism generation: unimolecular and bimolecular initiations (with $\mathrm{O}_{2}$ ), $\mathrm{H}$-abstractions from reactants by $\mathrm{H}, \mathrm{OH}, \mathrm{HO}_{2}, \mathrm{CH}_{3}, \mathrm{CHO}$, $\mathrm{CH}_{2} \mathrm{OH}, \mathrm{CH}_{3} \mathrm{O}, \mathrm{CH}_{3} \mathrm{OO}, \mathrm{C}_{2} \mathrm{H}_{5}$, peroxyheptyl and peroxyoctyl radicals, $\mathrm{C}-\mathrm{C}, \mathrm{C}-\mathrm{H}$, and $\mathrm{C}-\mathrm{O} \beta-$ scissions of alkyl and (di)hydroperoxyalkyl radicals, oxidations of alkyl radicals yielding conjugated alkene and $\mathrm{HO}_{2}$, additions of alkyl and hydroperoxyalkyl radicals on oxygen, isomerisations of alkyl and peroxy radicals, cyclic ethers formation from hydroperoxyalkyls radicals and disproportionations of peroxy radicals with $\mathrm{HO}_{2}$. 
The radicals generated in the primary mechanism are systematically decomposed until they reach a size that falls within the $\mathrm{C}_{0}-\mathrm{C}_{6}$ core reaction mechanism. Molecules generated in the primary mechanism are decomposed in the core mechanism if their size is small enough. If generated primary molecules are not present in the core reaction mechanism, their combustion reactions are generated in the secondary mechanism.

Given the large number of molecules for which decomposition reactions have to be generated in the secondary mechanism, it is not possible to apply the systematic approach used for primary mechanism. Therefore, the primary molecules which have the same molecular formulae and the same functional groups are lumped into a unique species in the secondary mechanism.

Decomposition reaction rules of lumped species, detailed in references ${ }^{11,15}$ are globalized reactions involving a one step process initiated by a unimolecular initiation, a $\mathrm{H}$-abstraction or an addition, yielding multiple fragments belonging to the core reaction mechanism.

Thermochemical data $\left(\Delta_{\mathrm{f}} \mathrm{H}^{\circ}{ }_{298 \mathrm{~K}}, \mathrm{~S}_{298 \mathrm{~K}}^{\circ}\right.$ and $\left.\mathrm{C}_{\mathrm{p}}(\mathrm{T})\right)$ of species generated in the PRF mechanism are automatically computed using the THERGAS software ${ }^{16}$ which is based on group additivity methods proposed by Benson. ${ }^{17}$ Kinetic data are also generated either using structure-reactivity correlations or thermo-kinetic relationships through the coupling of the EXGAS generator to the KINGAS code. ${ }^{10}$ To improve the agreement with ignition delays measured by Tanaka et al. ${ }^{9}$ in a RCM, several generated kinetic data were tuned, within their uncertainty limits. Table 1 presents all the reactions for which kinetic data were modified.

Table 1. All modifications applied to some generated kinetic data $\left(\mathrm{k}_{\mathrm{i}, \infty}=\mathrm{A}_{\mathrm{i}} \times \mathrm{T}^{\mathrm{ni}} \times \exp \left(-\mathrm{E}_{\mathrm{i}} / \mathrm{RT}\right)\right)$ of the PRF kinetic model. Units are in $\mathrm{cm}^{3}$, mol, s, cal. 


\begin{tabular}{|c|c|c|c|c|}
\hline \multirow{2}{*}{ Reaction $^{a}$} & \multicolumn{3}{|c|}{ generated $\mathbf{k}_{\mathbf{i}, \infty}$} & \multirow{2}{*}{$\begin{array}{l}\text { Modification adopted in } \\
k_{f, \infty}=A_{f} \times T^{n_{f}} \times \exp \left(-E_{f} / R T\right)\end{array}$} \\
\hline & $A i$ & $n i$ & $E i$ & \\
\hline $\mathrm{R} 28 \mathrm{C} 7 \mathrm{H} 15+\mathrm{O} 2=\mathrm{R} 39 \mathrm{C} 7 \mathrm{H} 15 \mathrm{O} 2 \mathrm{U}$ & $1.7010^{19}$ & -2.500 & 0 & $A_{f}=A_{i} \times 2$ \\
\hline $\mathrm{R} 29 \mathrm{C} 7 \mathrm{H} 15+\mathrm{O} 2=\mathrm{R} 40 \mathrm{C} 7 \mathrm{H} 15 \mathrm{O} 2 \mathrm{U}$ & $1.8010^{19}$ & -2.500 & 0 & $A_{f}=A_{i} \times 2$ \\
\hline $\mathrm{R} 30 \mathrm{C} 8 \mathrm{H} 17=\mathrm{R} 32 \mathrm{C} 8 \mathrm{H} 17$ & $2.9010^{08}$ & 1.000 & 15300 & $E_{f}=E_{i}-2000$ \\
\hline $\mathrm{R} 45 \mathrm{C} 8 \mathrm{H} 17 \mathrm{O} 2 \mathrm{U}=\mathrm{R} 85 \mathrm{C} 8 \mathrm{H} 17 \mathrm{O} 2 \mathrm{P}$ & $2.2010^{08}$ & 1.000 & 25000 & $A_{f}=A_{i} / 4$ \\
\hline $\mathrm{R} 36 \mathrm{C} 7 \mathrm{H} 15 \mathrm{O} 2 \mathrm{U}=\mathrm{R} 54 \mathrm{C} 7 \mathrm{H} 15 \mathrm{O} 2 \mathrm{P}$ & $1.1010^{09}$ & 1.000 & 25000 & $E_{f}=E_{i}-1500$ \\
\hline $\mathrm{R} 39 \mathrm{C} 7 \mathrm{H} 15 \mathrm{O} 2 \mathrm{U}=\mathrm{R} 64 \mathrm{C} 7 \mathrm{H} 15 \mathrm{O} 2 \mathrm{P}$ & $5.7010^{08}$ & 1.000 & 25000 & $E_{f}=E_{i}-1500$ \\
\hline $\mathrm{R} 40 \mathrm{C} 7 \mathrm{H} 15 \mathrm{O} 2 \mathrm{U}=\mathrm{R} 70 \mathrm{C} 7 \mathrm{H} 15 \mathrm{O} 2 \mathrm{P}^{\mathrm{b}}$ & $5.7010^{08}$ & 1.000 & 25000 & $E_{f}=E_{i}-1500$ \\
\hline $\mathrm{R} 40 \mathrm{C} 7 \mathrm{H} 15 \mathrm{O} 2 \mathrm{U}=\mathrm{R} 71 \mathrm{C} 7 \mathrm{H} 15 \mathrm{O} 2 \mathrm{P}^{\mathrm{c}}$ & $9.9010^{07}$ & 1.000 & 22000 & $E_{f}=E_{i}-1500$ \\
\hline $\mathrm{R} 26 \mathrm{C} 7 \mathrm{H} 15+\mathrm{O} 2=>\mathrm{C} 7 \mathrm{H} 14 \mathrm{Z}+\mathrm{HOO}$ & $3.9010^{12}$ & 0.000 & 5000 & $E_{f}=E_{i}+1500$ \\
\hline $\mathrm{R} 29 \mathrm{C} 7 \mathrm{H} 15+\mathrm{O} 2=>\mathrm{C} 7 \mathrm{H} 14 \mathrm{Z}+\mathrm{HOO}$ & $1.9010^{12}$ & 0.000 & 5000 & $E_{f}=E_{i}+1500$ \\
\hline $\mathrm{R} 29 \mathrm{C} 7 \mathrm{H} 15+\mathrm{O} 2=>\mathrm{C} 7 \mathrm{H} 14 \mathrm{Z}+\mathrm{HOO}$ & $1.9010^{12}$ & 0.000 & 5000 & $E_{f}=E_{i}+1500$ \\
\hline $\mathrm{C} 8 \mathrm{H} 18-1+\mathrm{R} 2 \mathrm{OH}=>\mathrm{H} 2 \mathrm{O}+\mathrm{R} 33 \mathrm{C} 8 \mathrm{H} 17$ & $2.6010^{06}$ & 2.000 & -765 & $A_{f}=A_{i} / 2$ \\
\hline $\mathrm{C} 8 \mathrm{H} 18-1+\mathrm{R} 2 \mathrm{OH}=>\mathrm{H} 2 \mathrm{O}+\mathrm{R} 30 \mathrm{C} 8 \mathrm{H} 17$ & $4.1010^{06}$ & 2.000 & 450 & $A_{f}=A_{i} / 2$ \\
\hline $\begin{array}{l}\mathrm{C} 8 \mathrm{H} 16 \mathrm{O} 3 \mathrm{KP}=>\mathrm{CO}+\mathrm{OH} \\
+\mathrm{R} 42 \mathrm{C} 4 \mathrm{H} 9+\mathrm{C} 2 \mathrm{H} 5 \mathrm{CHO}\end{array}$ & $3.010^{15}$ & 0.000 & 42000 & $A_{f}=A_{i} \times 2$ \\
\hline $\mathrm{C} 8 \mathrm{H} 18 \mathrm{O} 2 \mathrm{P}=>\mathrm{OH}+\mathrm{R} 42 \mathrm{C} 4 \mathrm{H} 9+\mathrm{C} 4 \mathrm{H} 8 \mathrm{OA}$ & $3.010^{15}$ & 0.000 & 43000 & $A_{f}=A_{i} \times 2 ; \mathrm{E}_{\mathrm{f}}=\mathrm{E}_{\mathrm{i}}-2000$ \\
\hline
\end{tabular}

\footnotetext{
${ }^{a}$ The description of the species involved in the reaction list can be found in the detailed kinetic model provided in supporting information. ${ }^{\mathrm{b}} 1,4-\mathrm{H}$-atom transfer. ${ }^{\mathrm{c}} 1,5 \mathrm{H}$-atom transfer.
}

Out of 2120 reactions generated for $n$-heptane and iso-octane low-temperature combustion, 15 were tuned to reach a better agreement with experimental data. Of course, the reactions presented in Table 1 are among the most sensitive ones for auto-ignition delays. 13 reactions of Table 1 are elementary reactions (in row order, from top to bottom): two additions of $n$-heptyl radicals on $\mathrm{O}_{2}$, one 1,4 $\mathrm{H}$-atom transfer in iso-octyl radicals, one 1,3-H-atom transfer in peroxyoctyl radicals, 4 isomerisations of peroxyheptyl radicals into hydroperoxyheptyl radicals $(1,5-\mathrm{H}-$ transfers for R36, R39 and R40 and 1,6-H-transfer for R40), 3 oxidation reactions of heptyl 
radicals, and two $\mathrm{H}$-abstractions by $\mathrm{OH}$ radical from iso-octane. The last two reactions of Table 1 are the global decomposition steps of lumped ketohydroperoxides formed in iso-octane mechanism.

The PRF kinetic mechanism features 2120 reactions and 395 species. The kinetic model proposed in this work is therefore optimized to accurately simulate HCCI combustion conditions, i.e., low equivalence ratios $(\approx 0.2$ to 0.5$)$ and temperatures, at high pressures $(\approx 20-40 \mathrm{~atm})$.

\section{RESULTS AND DISCUSSION}

Simulations of PRF auto-ignition in a RCM. Tanaka et al. reported auto-ignition delays of pure hydrocarbon fuels and mixtures in a Rapid Compression Machine for Homogeneous Charge Compression Ignition (HCCI) conditions, i.e., fuel lean and $\approx 40$ atm pressure. ${ }^{9}$ In particular, they studied the effect of the addition of several chemical compounds on PRF's ignition delays to determine suitable additive to control the ignition timing in HCCI engines. These experiments are therefore useful to validate our kinetic model developed to support the concept of autoignition control of fuel and air mixtures using photochemical isomerisation in HCCI combustion.

Several auto-ignition data are reported by Tanaka et al. ${ }^{9}$ for pure $n$-heptane (PRF0), iso-octane (PRF100) and blends of iso-octane and $n$-heptane which allow them to study several octane number fuels: PRF50, PRF75 and PRF90. These authors studied the effect of two additives on PRF90 auto-ignition delays: di-tert-butyl-peroxide (DTBP) and 2-ethyl-hexyl-nitrate (2EHN). 
1,3-CHD was not tested as an additive in their study, but its auto-ignition delay was measured as a pure fuel.

Using the PRF kinetic model presented above, RCM experimental data were simulated using Chemkin-Pro software. ${ }^{18}$ The absolute tolerance criterion of the solver was set to $1 \times 10^{-17}$ to avoid convergence issues. For all PRF simulations, the compression stage and the heat loss in the RCM were simulated using the physical model proposed by Tanaka et al. ${ }^{19}$, which is described in details in our work on 1-3-CHD combustion modeling. ${ }^{8}$ The definition of the simulated ignition delay times is established as the time at which $d P$ (pressure difference between fuel/air mixtures and $\mathrm{CO}_{2} /$ air mixtures with the same specific heat ratios) reached $20 \%$ of $d P_{\max }$ point. In our simulations the composition of the $\mathrm{CO}_{2}$ /air mixture was kept constant, as in the Tanaka et al. modelling work ${ }^{19}$.

Figure 2 presents a comparison between experimental and simulated ignition delays as a function of PRF composition.

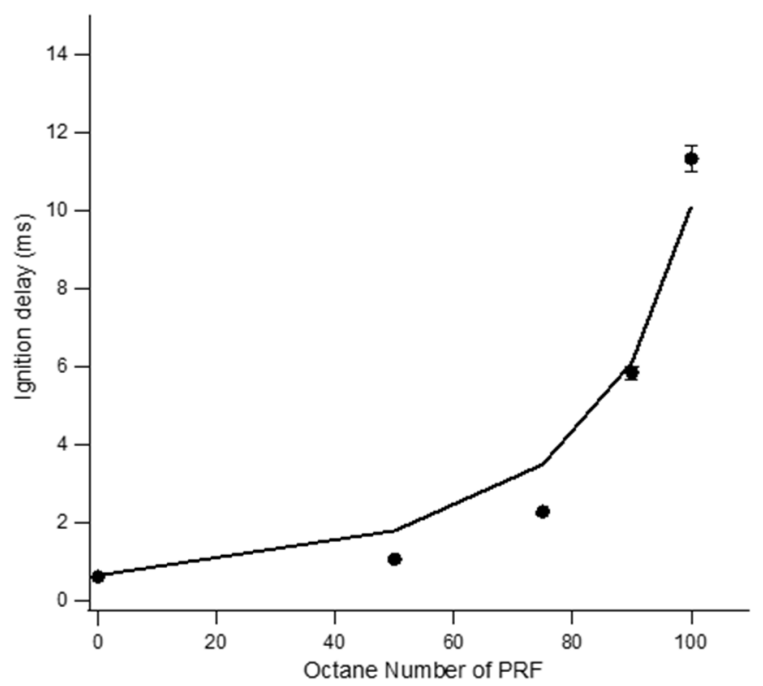

Figure 2. Ignition delays of several PRFs in a RCM. Initial temperature and pressure of $318 \mathrm{~K}$ and $0.1 \mathrm{MPa}$, with a 0.4 equivalence ratio. Temperature and pressure at top dead centre : $827 \mathrm{~K}$ 
and $41 \mathrm{~atm}^{9}$. Octane number is defined as the volume percentage of iso-octane in the PRF. PRF0 is $n$-heptane. Symbols: experimental data of Tanaka et al. ${ }^{9}$; lines: simulations.

The simulations performed with the PRF kinetic model developed in this study are in good agreement with the experimental data that were measured for $n$-heptane (PRF0), PRF50, PRF75, PRF90 and iso-octane (PRF100). Validations of the PRF were also performed as a function of equivalence ratios and temperatures. It can be noted that in the experiments of Tanaka et al. ${ }^{9}$, the temperatures after compression are ranging between 800 and $900 \mathrm{~K}$ and pressures are around 40 atm. These results are presented in Figure 3 and 4.

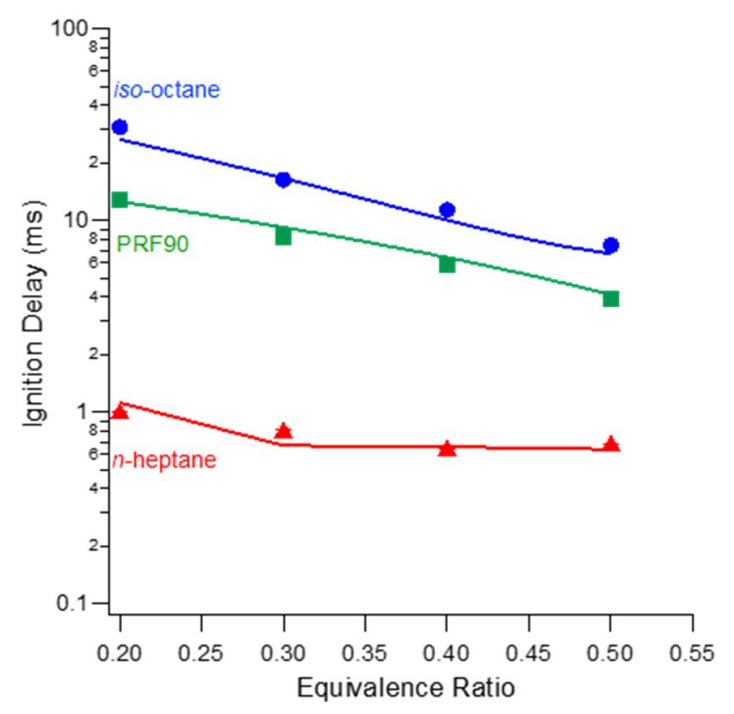

Figure 3. Ignition delays of $n$-heptane, PRF90 and iso-octane as a function of equivalence ratio in a RCM. Initial temperature and pressure of $318 \mathrm{~K}$ and $0.1 \mathrm{MPa}$. Symbols: experimental data of Tanaka et al. ${ }^{9}$; lines: simulations.

The PRF kinetic model is able to reproduce the main features of the experimental ignition delays as a function of equivalence ratio (Figure 3). For the lowest equivalence ratio $(\Phi=0.2)$, the simulated ignition delay of iso-octane is slightly underestimated. All the experiments were performed for lean conditions, ranging from 0.2 to 0.5 , to match HCCI combustion conditions. 
For $\Phi=0.2$, the simulated pressure profiles of the fuels do not feature a rise of pressure due to ignition as sharp as at higher equivalence ratios. Therefore, the uncertainty on the ignition delay ( $20 \%$ of $\mathrm{dP}$ maximum) is higher.

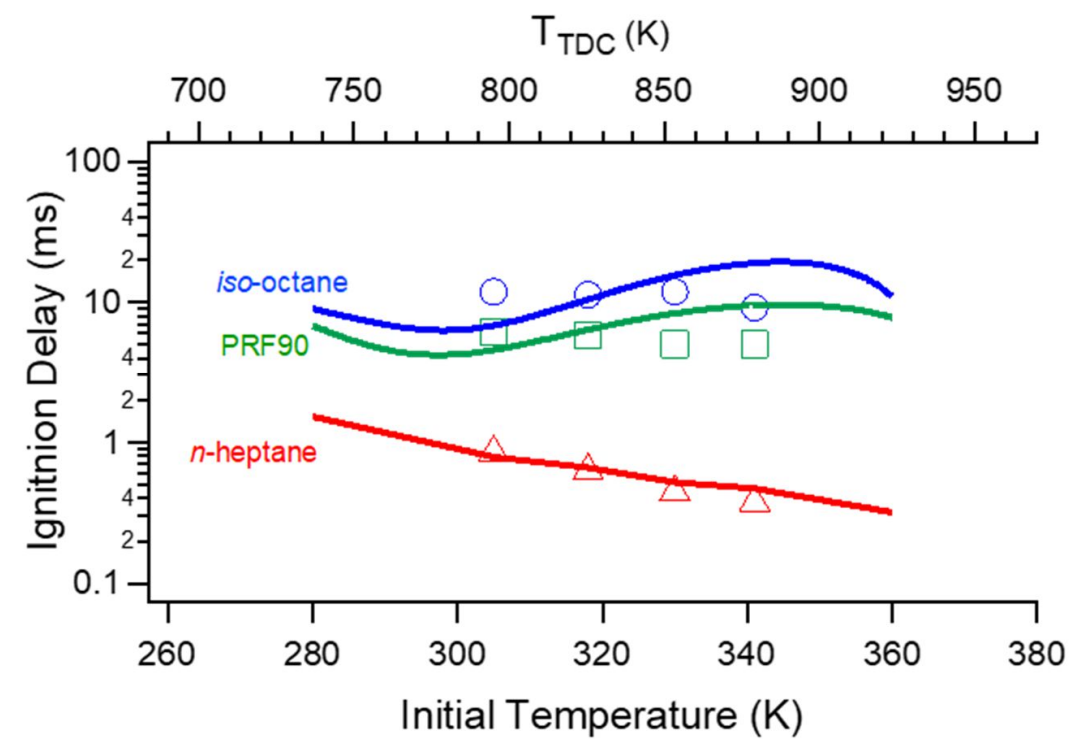

Figure 4. Ignition delays of $n$-heptane, PRF90 and iso-octane as a function of initial temperature $\left(\mathrm{T}_{\mathrm{i}}\right)$ in a RCM. Equivalence ratio of 0.4 and initial pressure of $0.1 \mathrm{MPa}$. Symbols: experimental data of Tanaka et al. ${ }^{9}$; lines: simulations.

The simulated ignition delays of $n$-heptane are in agreement with the experimental data over the temperature range studied. For iso-octane and PRF90 the simulated ignition delays are underestimated by a factor of 1.6 at an initial temperature of $305 \mathrm{~K}$ and overestimated (by a factor 2) for an initial temperature of $341 \mathrm{~K}$. The highest deviation is observed for iso-octane with a simulated ignition delay of $18.8 \mathrm{~ms}$ compared to an experimental value of $9.2 \mathrm{~ms}$ at an initial temperature of $341 \mathrm{~K}$.

From the validations presented in this section, it can be concluded that the detailed chemical kinetic model developed in this work can be used to simulate the combustion of a PRF under 
HCCI conditions with an acceptable degree of confidence. Additional validations on iso-octane can be found in the supplemental information.

Simulation of auto-ignition control in a RCM. The simulation of the impact of the addition of 1,3-CHD on the ignition delay of a PRF90 was achieved by adding the validated kinetic model of 1,3-CHD combustion ${ }^{8}$ to the PRF mechanism. The PRF/1,3-CHD mechanism contains 719 species and 3785 reactions. Before making comparisons between the effect of 1,3-CHD and 1,3,5-HT on the ignition delays of a PRF90, it is interesting to examine the effect of 1,3-CHD on the PRF90 reactivity. Figure 5 summarizes the simulated and experimental ignition delay times for the pure PRFs (presented in Figure 2) and $\mathrm{CHD}^{8}$ fuels. Ignition delays were computed using the compression and heat loss physical model.

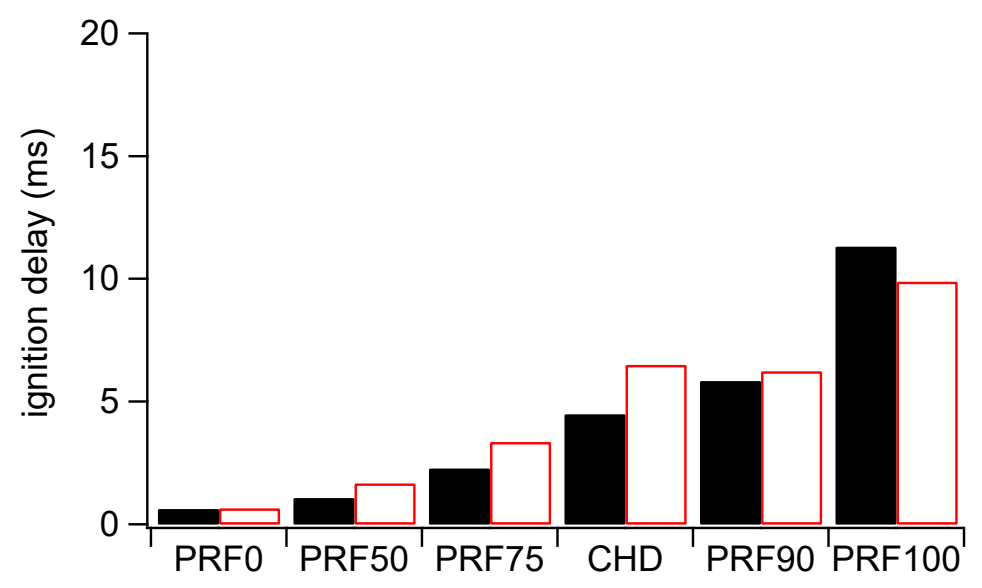

Figure 5: Simulated (red open bars) and experimental ${ }^{9}$ (black solid bars) ignition delay times in a RCM for different PRFs and pure CHD. Temperature and pressure at top dead center: $827 \mathrm{~K}$ and $41 \mathrm{~atm}$. Equivalence ratio of 0.4 .

It can be noted that the experimental ignition delay time of CHD $(4.5 \mathrm{~ms})$ is higher than the one of PRF75 (2.285 ms) despite a reported RON of 74.9 for CHD. This is not surprising since it has 
been shown in the literature that the correlation between measured ignition delays in a RCM and $\mathrm{RON}$ is not linear ${ }^{20}$ and strongly depends on the nature (linear or branched alkane, alkenes) of the fuel. ${ }^{21-23}$ Recently, Zhang et al. ${ }^{24}$ compared simulations performed in an adiabatic homogeneous batch reactor with a volume history of a real RON engine and an analogous RCM for n-butane combustion at low temperatures. They showed that in a RCM, ignition takes approximatively ten times longer to occur than in engine-like conditions.

Tanaka et al. ${ }^{9}$ measured ignition delays in a RCM for pure 1,3-CHD and PRF90. They also quantify the effect of two additives on the ignition delay of a PRF90: di-tert-butyl-peroxide (DTBP) and 2-ethylhexyl nitrate (EHN). These two additives are well known ignition enhancers of conventional fuels ${ }^{25,26}$ because of their ability to generate free radicals at low-temperature, through a relatively easy initial bond fission. These free radicals promote the hydrocarbon reactivity and contribute to decrease the ignition delay time of the hydrocarbon fuel / air mixtures. Figure 6 presents a comparison between experimental ignition delay times measured by Tanaka et al. ${ }^{9}$ for several volume percent of additive (DTBP and EHN) for PRF90 and simulations of PRF90 / 1,3-CHD mixtures in an homogeneous adiabatic reactor. 

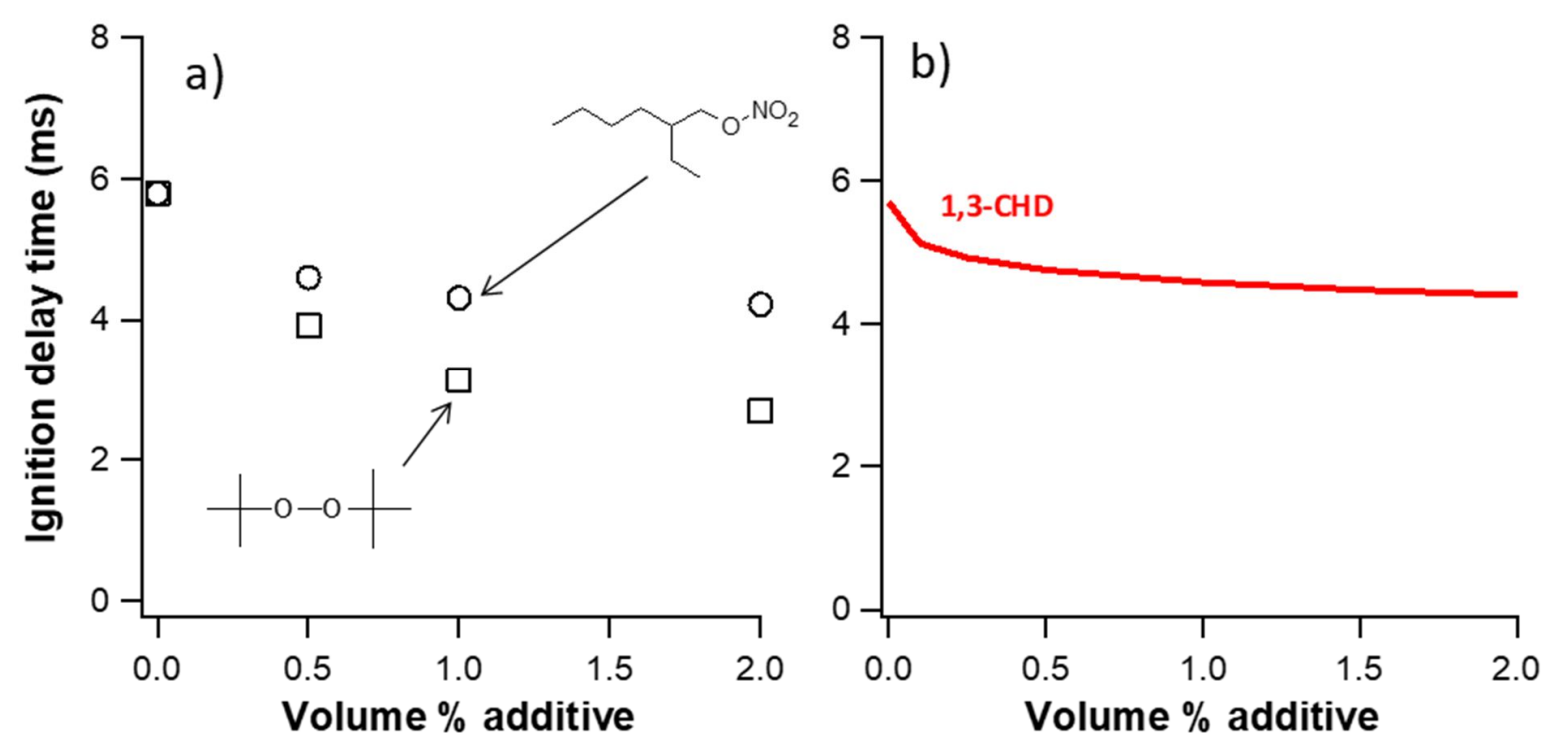

Figure 6. Ignition delays of PRF90 as a function of volume percent additives: a) experimental data of Tanaka et al. for DBTP (open squares) and $2 \mathrm{EHN}$ additives (open circles) in a RCM. ${ }^{9} \mathrm{~b}$ ) simulated ignition delays for 1,3-CHD additive. Conditions: equivalence ratio of 0.4 , compression temperature and pressure of $827 \mathrm{~K}$ and $41 \mathrm{~atm}$.

In Figure 6b, the simulations were performed in a batch reactor model, at a constant volume, and ignition delay time was defined as the time when a $400 \mathrm{~K}$ increment in temperature was reached. The simulations demonstrate that 1,3-CHD is an ignition enhancer as ignition delay times of PRF90 are decreased by $10 \%$ to $23 \%$ when $0.1 \%$ and $2 \%$ of $1,3-\mathrm{CHD}$ are added, respectively. The simulations predict that 1,3-CHD promotes auto-ignition to the same extent as 2EHN which is a well-known cetane improver in Diesel fuels. This prediction remains to be confirmed by an experimental study given the inherent uncertainty of the simulations, but, to the best of our knowledge, this is the first time that 1,3-CHD is demonstrated to be a potential cetane booster for HCCI combustion. This rather surprising high reactivity of 1,3-CHD was shown by Tanaka et al. ${ }^{9}$ who found that pure 1,3-CHD ignition delay was shorter than those of iso-octane, PRF90, cyclohexane, cyclohexene and 3-heptene, under the same conditions. 
The ignition booster quality of 1,3-CHD can be explained by a kinetic analysis of the simulations. The increased reactivity of hydrocarbon fuels due to conventional additives like DTBP and 2EHN is explained by their low bond dissociation energies that allows them to create free radicals, by unimolecular initiations, at relatively low temperatures. For example, the O-O bond dissociation energy in DTBP is $37.4 \mathrm{kcal} \mathrm{mol}^{-127}$ while the $\mathrm{O}-\mathrm{NO}_{2}$ bond initial fission in 2EHN requires an energy of $40.6 \mathrm{kcal} \mathrm{mol}^{-1} .^{28}$ In 1,3-CHD, the lowest bond dissociation energy (76.8 $\mathrm{kcal} \mathrm{mol}^{-1}$ ), involving the allylic $\mathrm{C}-\mathrm{H}$ bond fission, is much higher than the lowest bond energies involved in DTBP or 2-EHN, and an easy unimolecular initiation is not the cause of its ignition booster quality. From the simulations, it is observed that $1,3-\mathrm{CHD}$ is a cetane improver because of a relatively facile bimolecular initiation with $\mathrm{O}_{2}$ that creates two radicals: $1,3-\mathrm{CHD}+$ $\mathrm{O}_{2} \rightarrow$ cyclohexadienyl $+\mathrm{HO}_{2}$. This reaction features a low activation energy of $27 \mathrm{kcal} \mathrm{mol}^{-1}$, and its rate is increased under high-pressure conditions, such as those encountered in HCCI combustion. The easy $\mathrm{C}-\mathrm{H}$ beta bond fissions in cyclohexadienyl, yielding active $\mathrm{H}$-atoms and benzene, significantly contributes to the reactivity enhancement for 1,3-CHD. It is interesting to note that this $\beta$-scission is specific to this species and is favoured because it leads to the formation of very stable benzene, which is almost unreactive under the conditions studied here. ${ }^{29}$ The experimental activation energy reported by Gao et al. ${ }^{30}$ for this elementary reaction is 21.5 kcal mol${ }^{-1}$. The minor decomposition pathway of cyclohexadienyl by combination with $\mathrm{HO}_{2}$ also contributes, to a lesser extent, to the increased reactivity of 1,3-CHD because it leads to the formation of hydroperoxides.

The effect of pressure variation on the efficiency of 1,3-CHD as ignition improver was tested using simulations. Figure 7 presents the relative decrease of ignition delays due to the addition of $1 \%$ of $1,3-\mathrm{CHD}$ to a PRF90. The percentage decrease is defined as ( $\left.\tau_{\mathrm{PRF} 90 \mathrm{CHD}}-\tau_{\mathrm{PRF} 90}\right) / \tau_{\mathrm{PRF}} \mathrm{O}$, 
where $\tau_{\text {PRF90 }}$ and $\tau_{\text {PRF90CHD }}$ are the simulated ignition delays of PRF90 and 99\% PRF90 / 1\% 1,3CHD mixture, respectively.

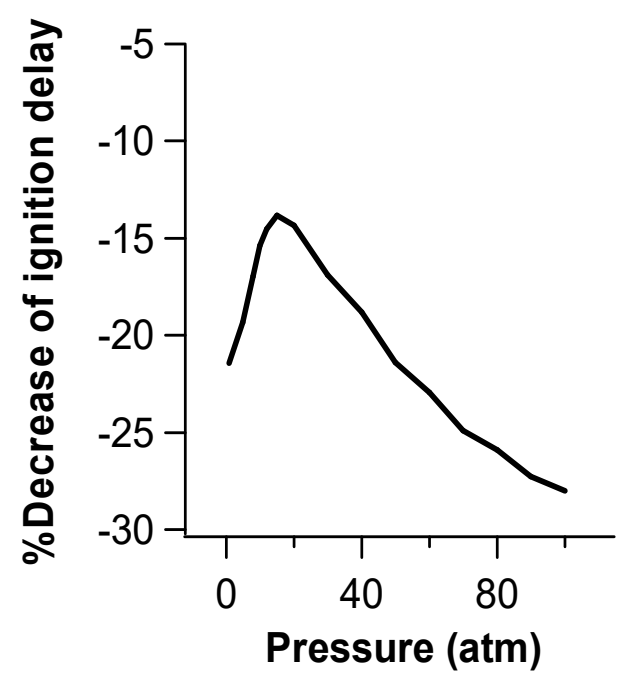

Figure 7. Percentage decrease (see text) in PRF90 ignition delay times due to the addition of vol.1\% of $1,3-\mathrm{CHD}$ as a function of pressure. Initial $\mathrm{T}=827 \mathrm{~K}$, equivalence ratio $=0.4$.

It can be seen in Figure 7 that the addition of 1,3-CHD in a PRF90 systematically decreases its ignition delays for pressures ranging from 1 to $100 \mathrm{~atm}$. The shape of the curve highlights a complex behaviour as function of pressure, with a decrease of ignition improvement from 1 to 15 atm, and a steady increase of the cetane boosting effect for pressures above $15 \mathrm{~atm}$. From 1 to 15 atm, some sensitive reactions of small species in the core reaction mechanism are in the fall-off region. This is particularly notable for the main inhibiting reaction (at this temperature) involving $\mathrm{H}$-atoms and $\mathrm{HO}_{2}$ radicals: $\mathrm{H}+\mathrm{O}_{2}+\mathrm{M}=\mathrm{HO}_{2}+\mathrm{M}$. When the pressure is increased from 1 to 15 atm, its rate constant is increased too, leading to a lowering of the reactivity. The rate of other inhibiting bimolecular reaction such as termination is also increased as pressure increases. For example, the rate of consumption of $\mathrm{HO}_{2}$ radical, through the termination reaction $\mathrm{HO}_{2}+\mathrm{HO}_{2}=$ 
$\mathrm{H}_{2} \mathrm{O}_{2}+\mathrm{O}_{2}$ increases with pressure. As pressures rise above $15 \mathrm{~atm}$, the competition between the inhibiting reactions in the core reaction mechanism and the main enhancing reaction which is the bimolecular initiation $1,3-\mathrm{CHD}+\mathrm{O}_{2}$ starts to turn in favor of the promoting effect.

These simulation indicate that 1,3-CHD could be an additive whose ignition enhancer effect can be controlled to some extent with pressure variations. A large number of 1,3-CHD derivatives could feature the same properties as long as easy bimolecular initiation with $\mathrm{O}_{2}$ and $\beta$-bond fission in the cyclohexadienyl derivative radical, yielding benzene and $\mathrm{R} \cdot$, are possible. It can be noted that the ignition enhancing effect of classical ignition boosters such as 2-EHN and DTBP could also be, in principle, controlled to some extent by pressure variation because their boosting quality rely on the fast release of small radicals in the system. As pressure will rise, there may be a competition between the inhibiting and the promoting bimolecular reactions. This could lead to variation in the ignition enhancing capabilities of the additive. To the best of our knowledge, no study has reported such behaviors, but simulations performed by a reviewer of this article, using Andrae's model ${ }^{25}$, showed that 2-EHN addition into a PRF90 leads to a similar behavior (under the conditions defined in Figure 7).

Another unique feature of 1,3-CHD is its ability to yield cis-1,3,5-hexatriene upon light activation. Simulations were performed in an ideal batch reactor to quantify the impact of each additive on the ignition delay times of a PRF90. Figure 8 presents the results obtained under the conditions of Tanaka et al. ${ }^{9}$, for different volume percent of additives. 


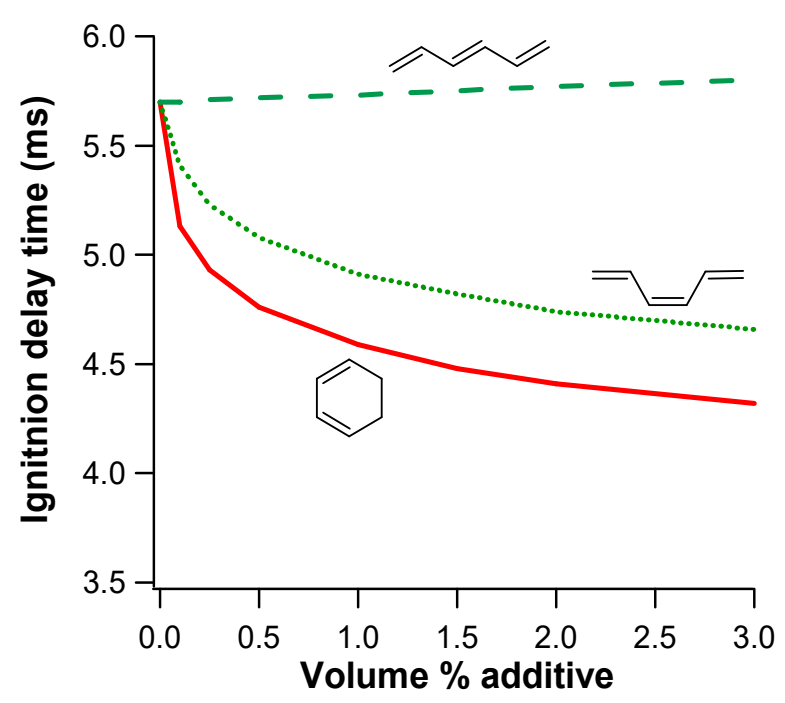

Figure 8. Ignition delays of PRF90 as a function of volume percent additives: 1,3-CHD (solid line), cis-1,3,5-HT (dotted line), trans-1,3,5-HT (dashed line). Conditions: equivalence ratio of 0.4 , temperature and pressure of $827 \mathrm{~K}$ and $40.1 \mathrm{~atm}$.

The simulations presented in Figure 8 show that the ignition delays of a PRF90 can be controlled through the transformation of 1,3-CHD into cis-1,3,5-HT. If no additive is included in the PRF90 mixture, an ignition delay of $5.7 \mathrm{~ms}$ is computed. The progressive addition of 1,3-CHD leads to a decrease of this ignition delay from $10 \%$ at 0.1 vol. $\%$ to $23 \%$ at 2 vol. $\%$. If $c i s-1,3,5-\mathrm{HT}$ is added to the PRF90 mixture, ignition delays are decreased to a lesser extent from 5\% at 0.1 vol.\% to $17 \%$ at 2 vol.\%. For comparison, simulations were performed for trans-1,3,5-HT and it is shown in Figure 8 that this additive slightly inhibits the reactivity. The observed differences in reactivity between cis- and trans-1,3,5-HT is explained by the fact that only cis-1,3,5-HT can form 1,3CHD through a pericyclic reaction. A reaction flux analysis performed at 50\% conversion of cis1,3,5-HT under the conditions of Figure 8 shows that $99.8 \%$ of $c i s-1,3,5-\mathrm{HT}$ is consumed by the pericyclic reaction yielding 1,3-CHD, which in turn is initially decomposed by bimolecular initiation with $\mathrm{O}_{2}$. The use of cis-1,3,5-HT as additive in a PRF90 mixture therefore induces an 
induction period, during which cis-1,3,5-HT is transformed into 1,3-CHD, that explain the observed differences in ignition delay times between the two isomers blended in PRF90. We observed in a previous study that the ignition delays of pure 1,3-CHD and cis-1,3,5-HT in air were almost identical in an adiabatic reactor because of the exothermic reaction $1,3,5-\mathrm{HT} \rightarrow 1,3-$ CHD. ${ }^{8}$ This effect is lessened here because a very small proportion of cis-1,3,5-HT is blended in the PRF90.

Simulation of auto-ignition timing control in HCCI combustion. Control over ignition timing was simulated under simplified HCCI operating conditions. Ignition was simulated for a mixture of PRF90 containing a molar fraction of $1 \% 1,3-\mathrm{CHD}$ partially converted to $1,3,5-\mathrm{HT}$. This was the same composition for which photochemical conversion was described by Minnaard and Havinga. $^{7}$

Ignition was modelled for a zero-dimensional single-zone HCCI engine model employing detailed chemical reaction kinetics. The simulations were performed using the Cantera 2.4.0 software tools in the Python 3.7 programming language. ${ }^{31}$ The thermodynamic engine process was simulated according to slider-crank equations. ${ }^{32}$ The engine represented one cylinder of a light-duty automotive engine having a bore diameter of $86 \mathrm{~mm}$, a stroke length of $86 \mathrm{~mm}$, a connecting-rod length of $160 \mathrm{~mm}$, and a swept volume of $499.56 \mathrm{cc}$. The reactant gases had an initial temperature of $\mathrm{T}_{\text {in }}=338 \mathrm{~K}$, and an initial pressure $\mathrm{P}_{\text {in }}=102 \mathrm{kPa}$ at the start of compression, representing naturally aspirated conditions and heat addition from the valves during the induction and charge preparation process. The engine air charge had molar fractions of $21 \% \mathrm{O}_{2}$ and $79 \% \mathrm{~N}_{2}$ to represent standard conditions without EGR. The start of the compression stroke was defined as $0^{\circ}$ crank angle (CA), and TDC as $180^{\circ} \mathrm{CA}$. Heat transfer 
from the reactants to the combustion chamber walls during the engine cycle was simulated using the semi-empirical model of Woschni. ${ }^{32}$

The ability of the photochemical isomerisation of 1,3-CHD to 1,3,5-HT to control ignition timing in an HCCI engine was investigated at constant equivalence ratio and constant engine speed operation. It was investigated how the photochemically active substance 1,3-CHD could change autoignition timing when present in a molar concentration of $1 \%$ in PRF-90 fuel. The engine operating conditions were a rotational speed of $2000 \mathrm{rpm}$, and an equivalence ratio of $\Phi=0.5$. A maximum indicated mean effective pressure (IMEP) of $1.15 \mathrm{MPa}$ was achieved for molar fractions of $99 \%$ PRF-90 $+1.0 \% 1,3-\mathrm{CHD}$, whilst for molar fractions of $99 \%$ PRF-90 + $1.0 \% 1,3,5$-HT the IMEP was reduced to $0.33 \mathrm{MPa}$, effectively suppressing ignition. This means that the photochemical conversion was effective in retarding the point of ignition by around $5^{\circ}$ CA which is equivalent to changing the inlet air temperature by about $10 \mathrm{~K}$. Figure 9 shows the cylinder pressure (a.) and apparent heat release rate of combustion (b.), after subtraction the heat transfer to the walls.
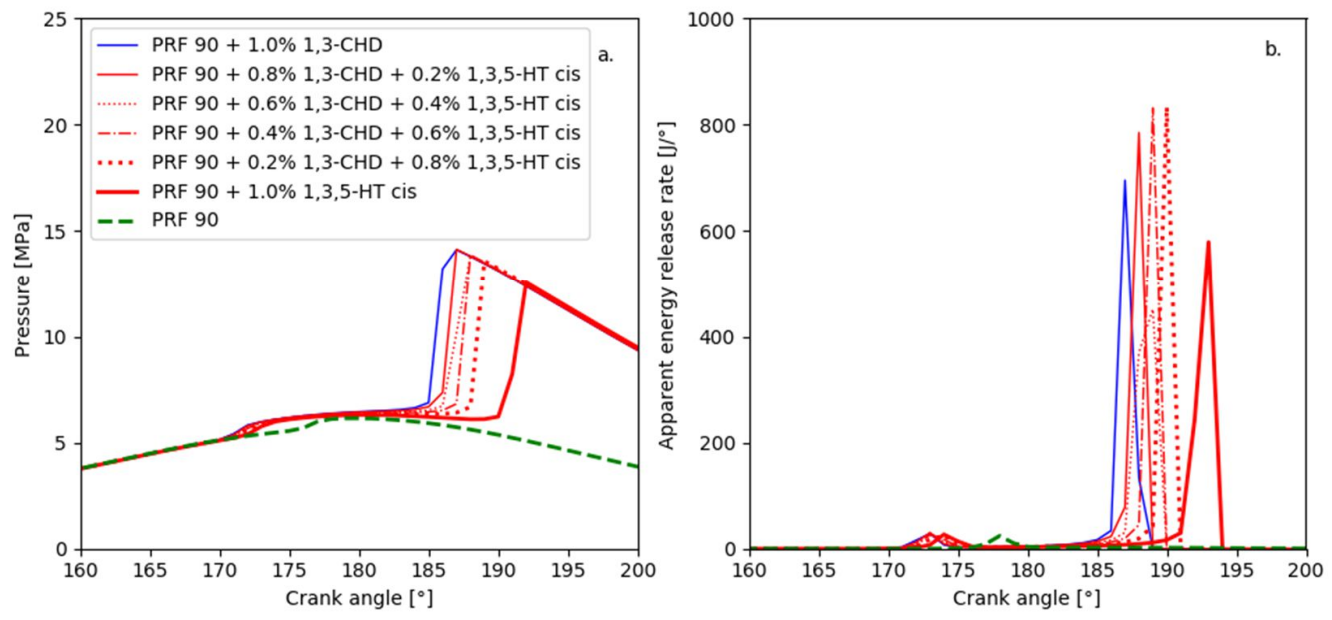
Figure 9. Influence of photochemical isomerisation reaction on cylinder pressure (a.) and apparent energy release rate (b.) of the engine cycle. HCCI engine operating conditions: Constant engine speed of $2000 \mathrm{rpm}$ and $\Phi=0.50$. Highest engine load $1.15 \mathrm{MPa}$ IMEP for $99 \%$ PRF-90 + $1.0 \% 1,3-C H D$.

Figure 9 shows that the photochemically unconverted fuel consisting of $1 \% 1,3-\mathrm{CHD}$ and 99 \% PRF-90 molar fractions resulted in earlier ignition than the partially photochemically isomerised fuels consisting of an increasing proportion of $c i s-1,3,5-\mathrm{HT}$, up to $0.8 \% 1,3,5-\mathrm{HT}+$ $0.2 \% 1,3-\mathrm{CHD}$ and $99 \%$ PRF-90, which corresponds to the same molar fractions achieved in the experiments of Minnaard and Havinga. ${ }^{7}$ The earlier ignition is visible in
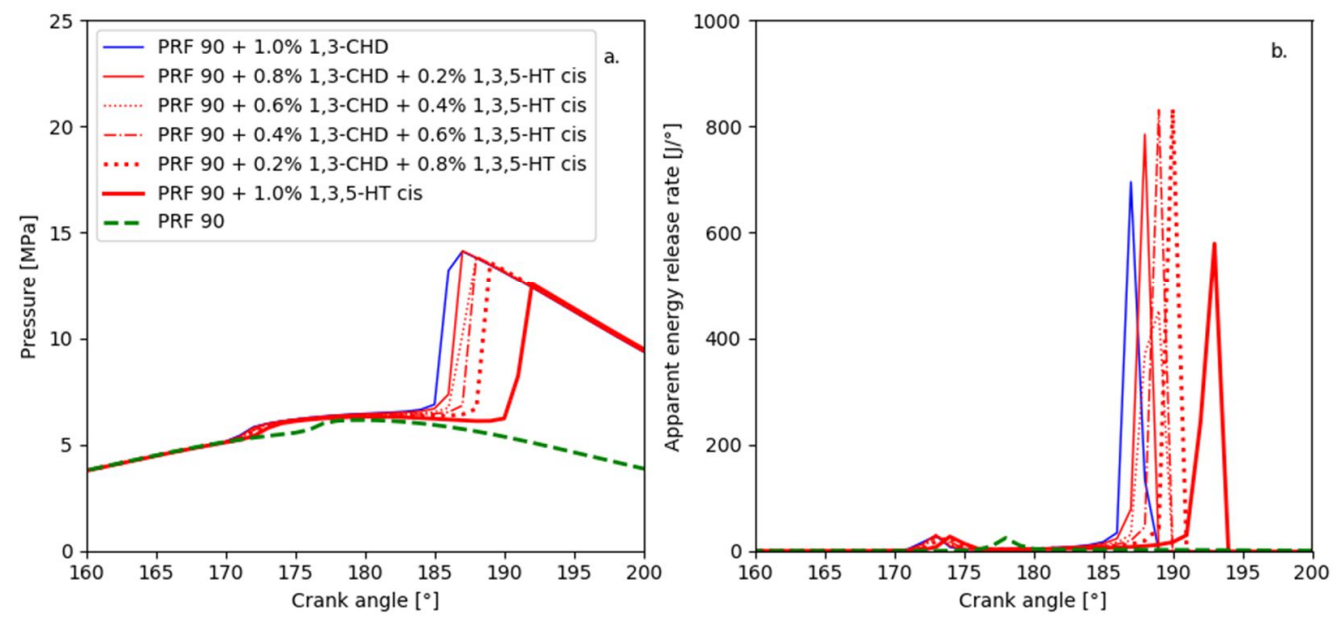

Figure 9 through the earlier heat release rate and the higher peak cylinder pressure.

Figure 10 presents the simulated global cylinder temperature as a function of crank angle. 


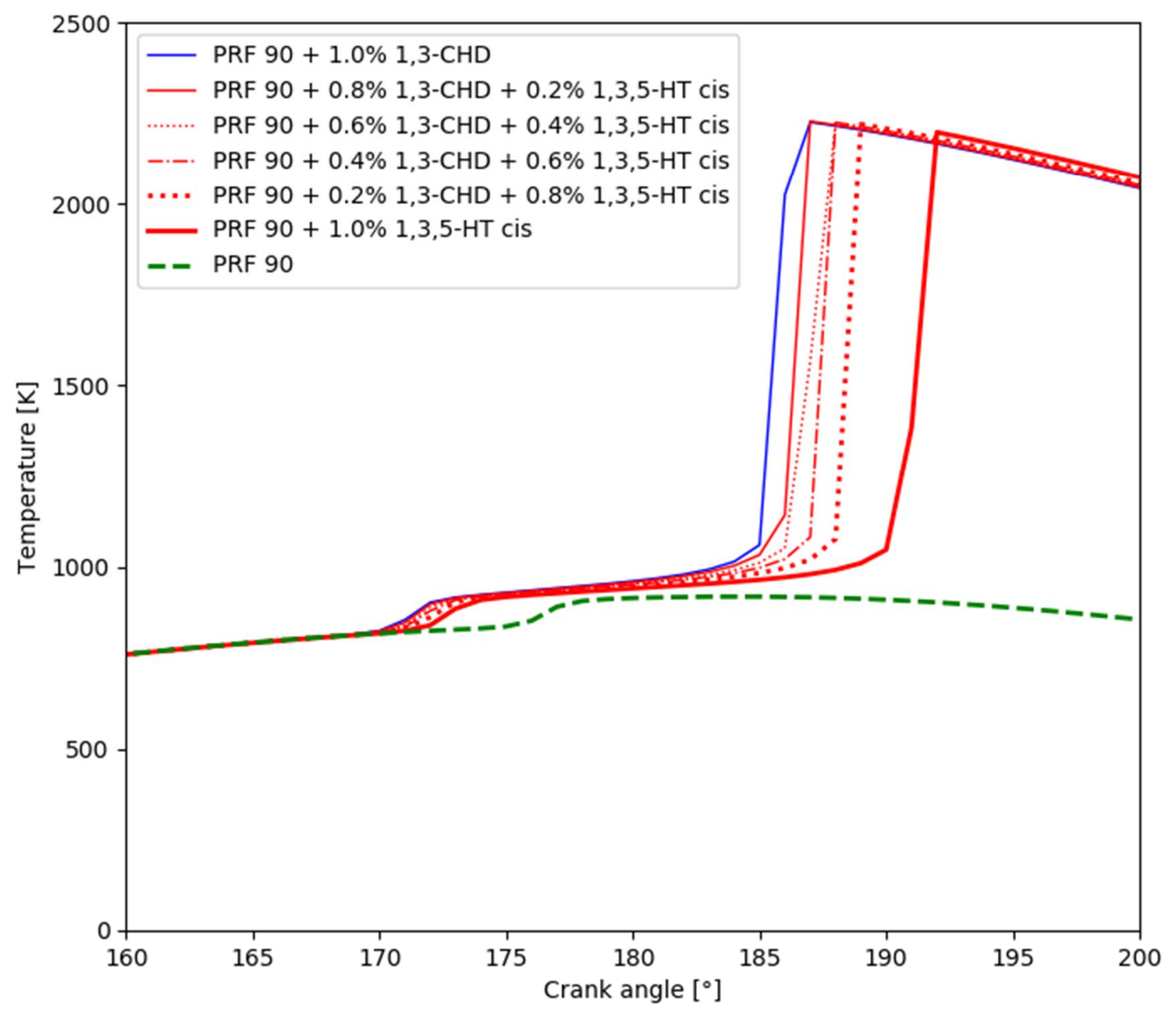

Figure 10. HCCI global cylinder temperature at constant engine speed of $2000 \mathrm{rpm}$ and $\Phi=0.50$. Highest engine load 1.2 MPa IMEP for $99 \%$ PRF-90 + $1.0 \%$ 1,3-CHD.

The chemical kinetic simulations showed that the photochemical conversion of 1,3-CHD to 1,3,5-HT retarded the timing of peak cylinder temperature. Figure 10 shows that the later heat release resulted in slightly lower and later peak cylinder temperatures for $1 \% 1,3,5-\mathrm{HT}$ and $99 \%$ PRF-90. The fuel consisting of $1 \%$ 1,3-CHD and $99 \%$ PRF-90 molar fractions had a faster 
reaction than $1 \% 1,3,5$-HT and $99 \%$ PRF-90, because cis-1,3,5-HT first had to isomerise into 1,3-CHD, before the combustion reactions, starting with its decomposition to the 1,3Cyclohexadienyl radical, could take place. Figure 11 shows the molar fraction of fuel molecules, $\mathrm{H}_{2} \mathrm{O}_{2}$ and $\mathrm{OH}$ intermediates, $\mathrm{CO}_{2}$ and $\mathrm{H}_{2} \mathrm{O}$, for $99 \%$ PRF-90 fuel containing either $1 \% 1,3-$ CHD or $1 \% 1,3,5-H T$.

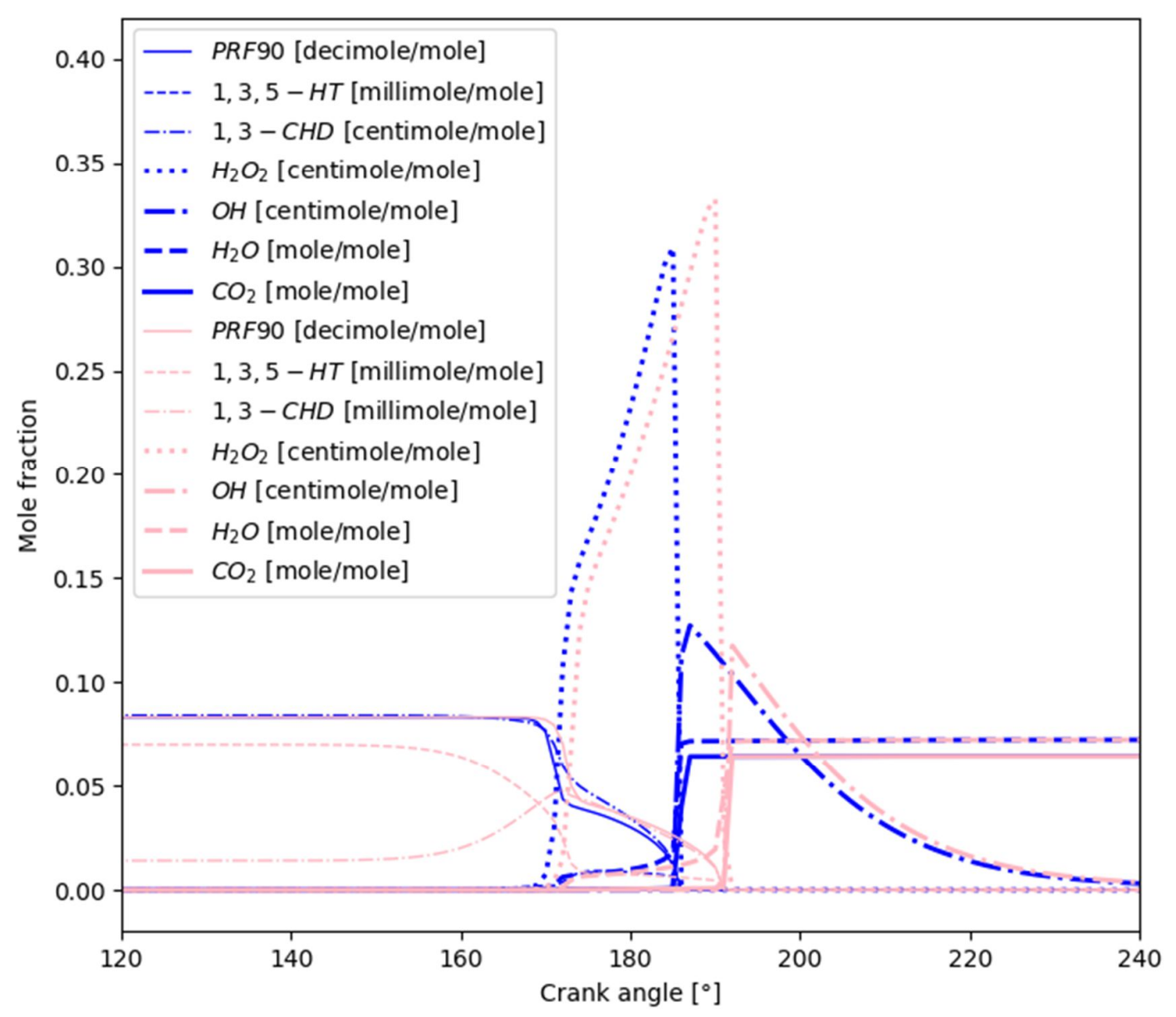

Figure 11. Species mole fraction development for $1 \% 1,3-\mathrm{CHD}$ and $99 \%$ PRF-90 (blue lines) and $1 \% 1,3,5$-HT and $99 \%$ PRF-90 (red lines). Equivalence ratio $\Phi=0.5$ and HCCI engine speed $\omega=2000 \mathrm{rpm}$. 
It is visible that formation of $\mathrm{H}_{2} \mathrm{O}_{2}$ occurred earlier for $1 \% 1,3-\mathrm{CHD}$ and $99 \%$ PRF-90 than for $1 \%$ 1,3,5-HTand $99 \%$ PRF-90, and that its concentration peaked sharply and was replaced by $\mathrm{OH}$ intermediates once high temperature ignition was reached. This was not the case for $1 \%$ 1,3,5-HT and $99 \%$ PRF-90, where no high temperature ignition occurred, and $\mathrm{H}_{2} \mathrm{O}_{2}$ survived the engine cycle. Decomposition of the main fuel, PRF-90, occurred after the decomposition of 1,3CHD and 1,3,5-HT, and was thus controlled by the decomposition of the latter in both cases.

Influence of fuel photochemical reaction on constant-pressure ignition delays. In addition to the engine simulations presented in the previous section, the ability of controlling the autoignition delay was investigated for isobaric ignition, over a wider range of pressure and temperature conditions. Constant pressure ignition allowed testing the fuel compositions at generic conditions more representative of those found in gas-turbine combustors. Autoignition can sometimes be used as a means of flame stabilisation in gas turbines, and has the advantage that it removes the need for pilot flames. ${ }^{33}$ Ignition can then either be controlled by adding a primary combustor in front of an ignition combustor ${ }^{34}$, or by changing the fuel composition. Figure 12 shows the calculated autoignition delays for $1 \% 1,3-\mathrm{CHD}$ and $99 \%$ PRF-90, $1 \%$ 1,3,5-HT and $99 \%$ PRF-90 and a $50 \%$ mixture of these two. The simulations were carried out for pressures of 1, 2, and $3 \mathrm{MPa}$, and temperatures of $800-1100 \mathrm{~K}$. 


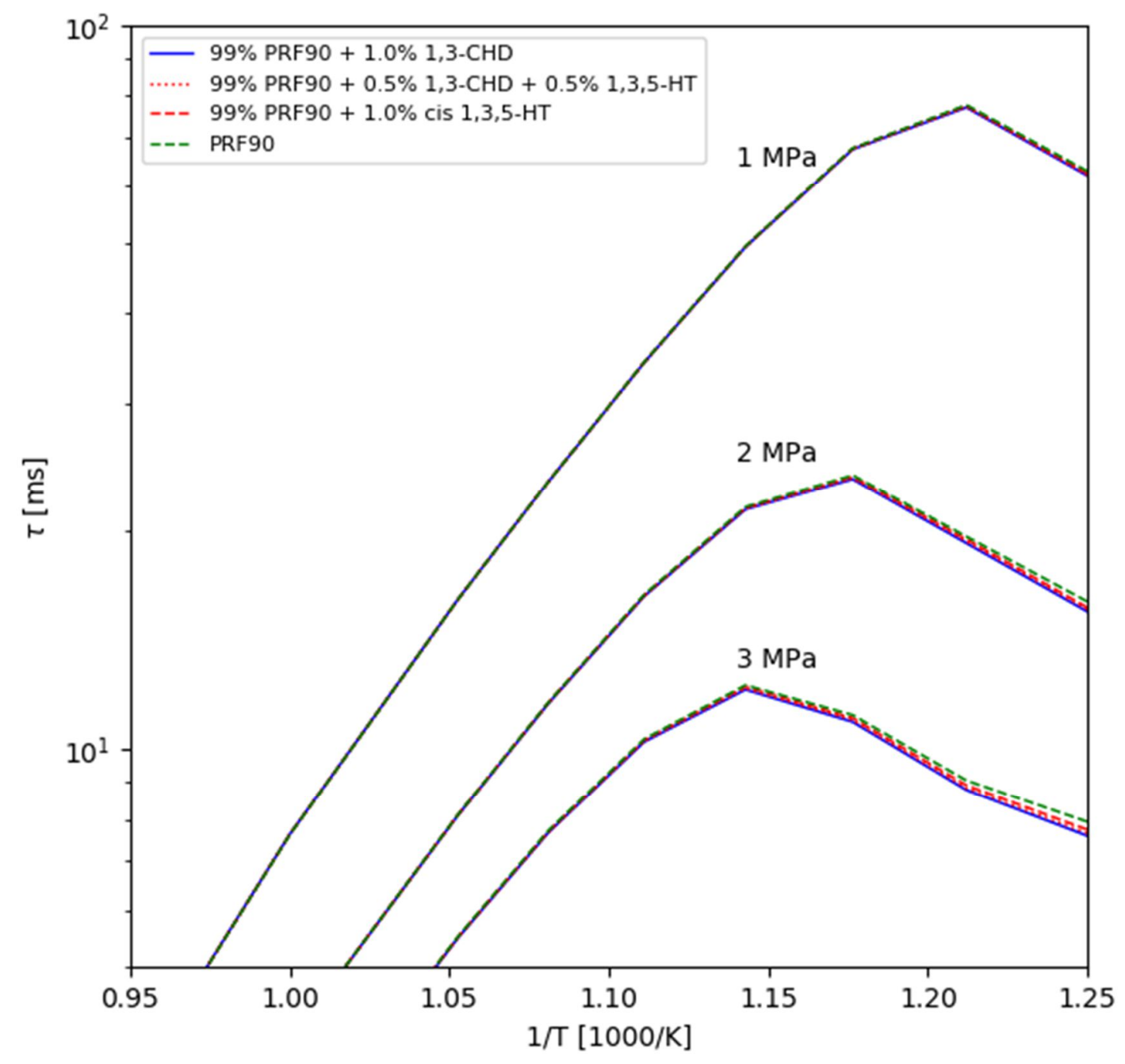

Figure 12. Constant pressure ignition delay for $1 \%$ 1,3-CHD and 99 \% PRF-90, 1 \% 1,3,5-HT and $99 \%$ PRF-90 and a 50\% mixture of these two at $\Phi=0.5$.

Figure 12 shows that the change in ignition delay was present over the entire range of conditions tested, but that it was very small. The highest fractional change of $4 \%$ in ignition delay was achieved at the condition of highest pressure $(3 \mathrm{MPa})$ and the lowest temperature $(800 \mathrm{~K})$. This showed that the variation in ignition delay was not very effective at isobaric conditions, 
especially at low pressures and high temperatures. The best operating conditions to obtain a large variation in ignition delay using the photochemical conversion of $1 \% 1,3-\mathrm{CHD}$ to $1 \% 1,3,5-\mathrm{HT}$ were thus found to be at high pressures and low temperatures.

\section{CONCLUSIONS}

A detailed chemical kinetic model for the combustion of PRF / 1,3-cyclohexadiene / 1,3,5hexatriene mixtures was developed in this work. The mechanism of the PRF was developed using an automatic generator. The trial model produced by the generator was then refined, through adjustment of several rate constants within their uncertainty limits, to accurately simulate auto-ignition delay times measured in a RCM. Validations of the PRF kinetic model showed that it can be used to satisfactory simulate HCCI combustion conditions (high-pressure, low equivalence ratio).

Based on the successful validations of pure PRF90/air and 1,3-CHD/air ignition delays, the effect of 1,3-CHD used as an additive in PRF90 was studied for the first time in the literature. The simulations predicted that $1,3-\mathrm{CHD}$ is a potential cetane booster which can enhance ignition to a comparable level of 2-ethylhexyl nitrate.

Kinetic analyses showed that the ignition enhancer quality of 1,3-CHD is due to successive favourable bimolecular initiation with $\mathrm{O}_{2}$ and $\mathrm{C}-\mathrm{H} \beta$-bond fission in cyclohexadienyl radical. These fundamental mechanisms are not the same as those involved in classical cetane booster and this work predicted that one can take advantage of this particular behaviour to control the extent of ignition enhancement with pressure.

In this study, the potential of adjusting the reactivity of a PRF90/1,3-CHD mixture, through photochemical transformation of 1,3-CHD into cis-1,3,5-HT, was predicted by simulations. At 
the same quantity of additive in PRF90, 1,3-CHD was predicted to enhance ignition delay times more than $c i s-1,3,5-\mathrm{HT}$.

Simple single zone kinetic simulations were used to illustrate its practical potential to engine applications. The simulations predicted that in reciprocating engines ignition could be controlled. The potential of 1,3-cyclohexadiene as a photochemically activated ignition controlling additive was thus illustrated using the chemical kinetic mechanism developed.

\section{AUTHOR INFORMATION}

\section{Corresponding Author}

*E-mail: baptiste.sirjean@univ-lorraine.fr

*E-mail: as@wmu.se

\section{SUPPORTING INFORMATION}

Detailed chemical kinetic model for combustion of PRF / 1,3-CHD / 1,3,5-HT and species nomenclature can be found in supplemental material. Additional validations for iso-octane are also presented.

\section{ACKNOWLEDGEMENTS}

The authors thank Prof. Heywood for his help on the specifications of RCM experiments performed at MIT. This work was granted access to the HPC resources of IDRIS under the allocation A0050807249 made by GENCI. High performance computing resources were partially provide by the EXPLOR centre hosted by the University of Lorraine. 


\section{REFERENCES}

1. Dec, J. E., Advanced compression-ignition engines - understanding the in-cylinder processes. Proceedings of the combustion institute 2009, 32 (2), 2727-2742.

2. Kokjohn, S. L.; Musculus, M. P.; Reitz, R. D., Evaluating temperature and fuel stratification for heat-release rate control in a reactivity-controlled compression-ignition engine using optical diagnostics and chemical kinetics modeling. Combustion and Flame 2015, 162 (6), 2729-2742.

3. Reitz, R. D., Directions in internal combustion engine research. Combustion and Flame 2013, 1 (160), 1-8.

4. Xu, H.; Wyszynski, M.; Megaritis, A.; Yap, D.; Wilson, T.; Qiao, J.; Richardson, S.; Golunski, S.; Peucheret, S. J. I. j. o. e. r., Research on expansion of operating windows of controlled homogeneous auto-ignition engines. 2007, 8 (1), 29-40.

5. Schönborn, A.; Hellier, P.; Aliev, A. E.; Ladommatos, N., Ignition control of homogeneous-charge compression ignition (HCCI) combustion through adaptation of the fuel molecular structure by reaction with ozone. Fuel 2010, 89 (11), 3178-3184.

6. Schönborn, A., A 'smart' fuel of photochemically-controlled reactivity. Fuel 2016, 165, 389-396.

7. Minnaard, N.; Havinga, E., Some aspects of the solution photochemistry of 1, 3cyclohexadiene,(Z)-and (E)-1, 3, 5-hexatriene. Recueil des Travaux Chimiques des Pays-Bas 1973, 92 (12), 1315-1320.

8. Schönborn, A.; Le, M. D.; Fournet, R.; Glaude, P.-A.; Warth, V.; Sirjean, B., Autoignition control using an additive with adaptable chemical structure. Part I: Development of a kinetic model for 1, 3-cyclohexadiene and 1,3, 5-hexatriene combustion. Combustion and Flame 2019, 205, 466-483.

9. Tanaka, S.; Ayala, F.; Keck, J. C.; Heywood, J. B., Two-stage ignition in HCCI combustion and HCCI control by fuels and additives. Combustion and Flame 2003, 132 (1-2), 219-239.

10. Warth, V.; Stef, N.; Glaude, P.; Battin-Leclerc, F.; Scacchi, G.; Côme, G., Computeraided derivation of gas-phase oxidation mechanisms: application to the modeling of the oxidation of n-butane. Combustion and Flame 1998, 114 (1-2), 81-102.

11. Buda, F.; Bounaceur, R.; Warth, V.; Glaude, P.-A.; Fournet, R.; Battin-Leclerc, F., Progress toward a unified detailed kinetic model for the autoignition of alkanes from $\mathrm{C} 4$ to $\mathrm{C} 10$ between 600 and 1200 K. Combustion and Flame 2005, 142 (1-2), 170-186.

12. Fournet, R.; Bauge, J.; Battin-Leclerc, F., Experimental and modeling of oxidation of acetylene, propyne, allene and 1, 3-butadiene. International journal of chemical kinetics 1999, 31 (5), 361-379.

13. Wang, H.; You, X.; Joshi, A. V.; Davis, S. G.; Laskin, A.; Egolfopoulos, F.; Law, C. K.; Version II, U. M. High-temperature combustion reaction model of H2/ CO/C1-C4 Compounds.; http://ignis. usc. edu/USC_Mech_II. htm: 2007.

14. Sirjean, B.; Fournet, R.; Glaude, P.-A.; Battin-Leclerc, F.; Wang, W.; Oehlschlaeger, M. A., Shock tube and chemical kinetic modeling study of the oxidation of 2, 5-dimethylfuran. The Journal of Physical Chemistry A 2013, 117 (7), 1371-1392.

15. Biet, J.; Hakka, M. H.; Warth, V.; Glaude, P.-A.; Battin-Leclerc, F., Experimental and modeling study of the low-temperature oxidation of large alkanes. Energy \& Fuels 2008, 22 (4), 2258-2269. 
16. Muller, C.; Michel, V.; Scacchi, G.; Côme, G.-M., THERGAS: a computer program for the evaluation of thermochemical data of molecules and free radicals in the gas phase. Journal de chimie physique 1995, 92, 1154-1178.

17. Benson, S. W., Thermochemical kinetics. Wiley: 1976.

18. CHEMKIN-PRO, R., 15112, Reaction Design. Inc., San Diego, CA 2011.

19. Tanaka, S.; Ayala, F.; Keck, J. C., A reduced chemical kinetic model for HCCI combustion of primary reference fuels in a rapid compression machine. Combustion and Flame 2003, 133 (4), 467-481.

20. Sarathy, S. M.; Farooq, A.; Kalghatgi, G. T., Recent progress in gasoline surrogate fuels. Progress in Energy and Combustion Science 2018, 65, 67-108.

21. Zhang, K.; Banyon, C.; Burke, U.; Kukkadapu, G.; Wagnon, S. W.; Mehl, M.; Curran, H. J.; Westbrook, C. K.; Pitz, W. J., An experimental and kinetic modeling study of the oxidation of hexane isomers: Developing consistent reaction rate rules for alkanes. Combustion and Flame 2019, 206, 123-137.

22. Westbrook, C.; Sjöberg, M.; Cernansky, N., A new chemical kinetic method of determining RON and MON values for single component and multicomponent mixtures of engine fuels. Combustion and Flame 2018, 195, 50-62.

23. Westbrook, C. K.; Pitz, W. J.; Mehl, M.; Glaude, P.-A.; Herbinet, O.; Bax, S.; BattinLeclerc, F.; Mathieu, O.; Petersen, E. L.; Bugler, J., Experimental and kinetic modeling study of 2-methyl-2-butene: allylic hydrocarbon kinetics. The Journal of Physical Chemistry A 2015, 119 (28), 7462-7480.

24. Zhang, P.; Yee, N. W.; Filip, S. V.; Hetrick, C. E.; Yang, B.; Green, W. H., Modeling study of the anti-knock tendency of substituted phenols as additives: an application of the reaction mechanism generator (RMG). Physical Chemistry Chemical Physics 2018, 20 (16), 10637-10649.

25. Andrae, J., Semidetailed Kinetic Model for Gasoline Surrogate Fuel Interactions with the Ignition Enhancer 2-Ethylhexyl Nitrate. Energy \& Fuels 2015, 29 (6), 3944-3952.

26. Clothier, P.; Aguda, B.; Moise, A.; Pritchard, H., How do diesel-fuel ignition improvers work? Chemical Society Reviews 1993, 22 (2), 101-108.

27. Batt, L.; Benson, S. W., Pyrolysis of Di-tertiary Butyl Peroxide: Temperature Gradients and Chain Contribution to the Rate. The Journal of chemical physics 1962, 36 (4), 895-901.

28. Luo, Y.-R., Handbook of bond dissociation energies in organic compounds. CRC press: 2002.

29. Herbinet, O.; Husson, B.; Ferrari, M.; Glaude, P.-A.; Battin-Leclerc, F., Low temperature oxidation of benzene and toluene in mixture with n-decane. Proceedings of the Combustion Institute 2013, 34 (1), 297-305.

30. Gao, Y.; DeYonker, N. J.; Garrett III, E. C.; Wilson, A. K.; Cundari, T. R.; Marshall, $\mathrm{P}$., Enthalpy of formation of the cyclohexadienyl radical and the $\mathrm{C}-\mathrm{H}$ bond enthalpy of 1, 4cyclohexadiene: An experimental and computational re-evaluation. The Journal of Physical Chemistry A 2009, 113 (25), 6955-6963.

31. Goodwin, D. G.; Speth, R. L.; Moffat, H. K.; Weber, B. W., Cantera: An object-oriented software toolkit for chemical kinetics, thermodynamics, and transport processes. Version 2.2. 1. https://www.cantera.org, 2018. Version 2.4.0. doi:10.5281/zenodo.1174508 2018.

32. Heywood, J. B., Internal combustion engine fundamentals; Chapter 10: Combustion in Compression-Ignition Engines. New York: McGraw-Hill: 1988. 
33. Güthe, F.; Hellat, J.; Flohr, P. J. J. o. E. f. G. T.; Power, The reheat concept: the proven pathway to ultralow emissions and high efficiency and flexibility. 2009, 131 (2), 021503.

34. Guyot, D.; Tea, G.; Appel, C., Low NOx lean premix reheat combustion in Alstom GT24 gas turbines. Journal of Engineering for Gas Turbines and Power 2016, 138 (5), 051503. 